\title{
The terpenes camphene and alpha-bisabolol inhibit inflammatory and neuropathic pain via Cav3.2 T-type calcium channels
}

\author{
Vinicius M. Gadotti ${ }^{\dagger}$, Sun Huang ${ }^{\dagger}$ and Gerald W. Zamponi ${ }^{*}$ (i)
}

\begin{abstract}
T-type calcium channels are known molecular targets of certain phytocannabinoids and endocannabinoids. Here we explored the modulation of Cav3.2 T-type calcium channels by terpenes derived from cannabis plants. A screen of eight commercially available terpenes revealed that camphene and alpha-bisabolol mediated partial, but significant inhibition of Cav3.2 channels expressed in ts A-201 cells, as well as native T-type channels in mouse dorsal root ganglion neurons. Both compounds inhibited peak current amplitude with IC50s in the low micromolar range, and mediated an additional small hyperpolarizing shift in half-inactivation voltage. When delivered intrathecally, both terpenes inhibited nocifensive responses in mice that had received an intraplantar injection of formalin, with alpha-bisabolol showing greater efficacy. Both terpenes reduced thermal hyperalgesia in mice injected with Complete Freund's adjuvant. This effect was independent of sex, and absent in Cav3.2 null mice, indicating that these compounds mediate their analgesic properties by acting on Cav3.2 channels. Both compounds also inhibited mechanical hypersensitivity in a mouse model of neuropathic pain. Hence, camphene and alpha-bisabolol have a wide spectrum of analgesic action by virtue of inhibiting Cav3.2 T-type calcium channels.
\end{abstract}

Keywords: Pain, Terpenes, Bisabolol, Camphene, T-type, Calcium channels, Cannabis

\section{Introduction}

Cav3.2 T-type calcium channels are important mediators of nociceptive signalling in the primary afferent pain pathway $[1,2]$ by regulating affent fiber and spinal cord interneuron activity, and synaptic communication in the spinal cord [3-7]. Cav3.2 channel expression is enhanced in a number of painful conditions [8-12], and conversely pharmacological inhibition [13] or molecular biological depletion [14] of these channels has analgesic effects. Hence, it is desriable to identify bioavailable inhibitors of Cav3.2 channels as potential analgesics.

\footnotetext{
*Correspondence: zamponi@ucalgary.ca

'Vinicius M. Gadotti and Sun Huang these authors contributed equally Department of Physiology and Pharmacology, Hotchkiss Brain Institute, Alberta Children's Hospital Research Institute, University of Calgary, AB T2N 4N1 Calgary, Canada
}

It is well established that cannabinoids derived from cannabis have analgesic properties [15-19]. Although, many are potent agonists of CB1 and/or CB2 cannabinoid receptors, there is evidence that phytocannabinoids such as Delta(9)-Tetrahydrocannabinol (THC) and cannabidiol (CBD) as well as several endocannabinoids also act on other molecular targets, including sodium and TRPV1 channels [20-22]. Cav3.2 calcium channels can be inhibited by certain types of synthetic cannabinoids $[23,24]$. They are also potently blocked the endocannabinoids anandamide and $\mathrm{N}$-arachidonoyl glycine [25, 26], suggesting the possibility that the analgesic actions of these endocannabinoids may at least in part be due to inhibition of T-type calcium channels. This is supported by a study by Barbara and colleagues [27] who attributed the analgesic effects of certain endocannabinoids to T-type calcium channel inhibition. Furthermore, THC original author(s) and the source, provide a link to the Creative Commons licence, and indicate if changes were made. The images or other third party material in this article are included in the article's Creative Commons licence, unless indicated otherwise in a credit line to the material. If material is not included in the article's Creative Commons licence and your intended use is not permitted by statutory regulation or exceeds the permitted use, you will need to obtain permission directly from the copyright holder. To view a copy of this licence, visit http://creativecommons.org/licenses/by/4.0/. The Creative Commons Public Domain Dedication waiver (http://creativeco mmons.org/publicdomain/zero/1.0/) applies to the data made available in this article, unless otherwise stated in a credit line to the data. 
and CBD block Cav3.1 and Cav3.2 calcium channels [28], altogether revealing a striking action of a range of cannabinoid compounds on T-type calcium channels.

Terpenes are compounds that can give plants their distinctive smell, and a number of different types of terpenes are found in cannabis plants at high concentrations along with cannabinoids [29]. Terpenes alone and in combination with cannabinoids have been shown to exert medicinal effects on patients with anxiety disorders (reviewed in Ref. [30]) and are being explored as possible analgesics in clinical studies (https://clinicaltrials.gov/ct2/show/ NCT04451863). We thus wondered if terpenes may also exhibit inhibitory actions on Cav3.2 calcium channels, and if so, whether they may be biologically active in pain models. Here we show that alpha-bisabolol and camphene mediate Cav3.2 channel inhibition and analgesia in mouse models of inflammatory and neuropathic pain.

\section{Materials and methods}

\section{Cell culture and transient transfection}

Human embryonic kidney cells (HEK) tsA-201 cells were grown to $80-90 \%$ confluence at $37{ }^{\circ} \mathrm{C}\left(5 \% \mathrm{CO}_{2}\right)$ in Dulbecco's modified Eagle's medium (Life Technologies, Grand Island, NY). The medium was supplemented with $10 \%$ (vol/vol) fetal bovine serum (Gibco, Thermo Scientific, Pittsburgh, PA), $200 \mathrm{U} / \mathrm{ml}$ penicillin, and $0.2 \mathrm{mg} / \mathrm{ml}$ streptomycin (Life Technologies, Grand Island, NY). Cells were suspended with $0.25 \%$ trypsin/ ethylenediaminetetraacetic acid and plated onto glass cover slips in $10 \mathrm{~cm}$ culture dishes (Thermo Scientific, Pittsburgh, PA) at $10 \%$ confluence $6 \mathrm{~h}$ before transfection. The transfections were conducted by a standard calcium phosphate method. For each plate, $5 \mu \mathrm{g}$ of Cav3.2, Cav3.1 or Cav3.3, and $0.5 \mu \mathrm{g}$ of green fluorescent protein cDNA were co-transfected. The cells were first cultured at $37{ }^{\circ} \mathrm{C}$ and then transferred to $30^{\circ} \mathrm{C} 16-18 \mathrm{~h}$ later following the medium change. The cells were kept at $30^{\circ} \mathrm{C}$ for at least two days before recording. Dorsal root ganglion (DRG) neurons were prepared as described by us previously, with the exception that mouse tissue was used in the present study instead of rat [31, 32]. In brief, DRG from 6- to 7-week-old C57 male mice were incubated with $4 \mathrm{mg} / \mathrm{ml}$ collagenase (Gibco, Cat\#17018-029) and $40 \mu \mathrm{l} / \mathrm{ml}$ papain (Worthington, Cat\#LS003126) in culture medium (DMEM (Gibco, Cat\#11995) supplemented with $10 \%$ heat-inactivated fetal bovine serum (Gibco, Cat\#26140-079) and 1\% penicillin/Streptomycin (Gibco, Cat\#15,140-122)) at $37^{\circ} \mathrm{C}$ for $30 \mathrm{~min}$, and then, $1 \mu \mathrm{g} / \mathrm{ml}$ DNase (Sigma, Cat\#D5025) at $37^{\circ} \mathrm{C}$ for another $10 \mathrm{~min}$, followed by washing and mechanical trituration. Cells were plated on glass coverslips pretreated with Poly-D-Lysine (Sigma, Cat\#P7280) and Laminin (Sigma, Cat\#L2020) and kept at $37^{\circ} \mathrm{C}$ in $5 \% \mathrm{CO}_{2}$ incubator.

\section{Whole-cell patch clamp recordings}

Eight terpenes (Toronto Research Chemicals, see Fig. 1a) were selected for testing on Cav3.2 channels by wholecell patch clamp recordings. Compounds were prepared as a stock solution of $50 \mathrm{mM}$. Cells on the glass coverslip were transferred into a $35 \mathrm{~mm} \times 10 \mathrm{~mm}$ dish (Corning, Corning, NY) filled with $2 \mathrm{ml}$ of external solution. The external solution contained $40 \mathrm{mM} \mathrm{TEACl}, 65 \mathrm{mM} \mathrm{CsCl}$, $20 \mathrm{mM} \mathrm{BaCl}, 1 \mathrm{mM} \mathrm{MgCl} 2,10 \mathrm{mM}$ HEPES and $10 \mathrm{mM}$ glucose, $\mathrm{pH}$ was adjusted to 7.4. The glass pipettes (Sutter Instrument Co., Novato, CA, 3-5 M $\Omega$ ) were filled with internal solution. The internal solution contained $140 \mathrm{mM} \mathrm{CsCl}, 2.5 \mathrm{mM} \mathrm{CaCl}, 1 \mathrm{mM} \mathrm{MgCl} 2,5 \mathrm{mM}$ EGTA, $10 \mathrm{mM}$ HEPES, $2 \mathrm{mM} \mathrm{Na}$-ATP and $0.3 \mathrm{mM} \mathrm{Na}$ GTP, $\mathrm{pH}$ was adjusted to 7.3. The patch clamp recordings

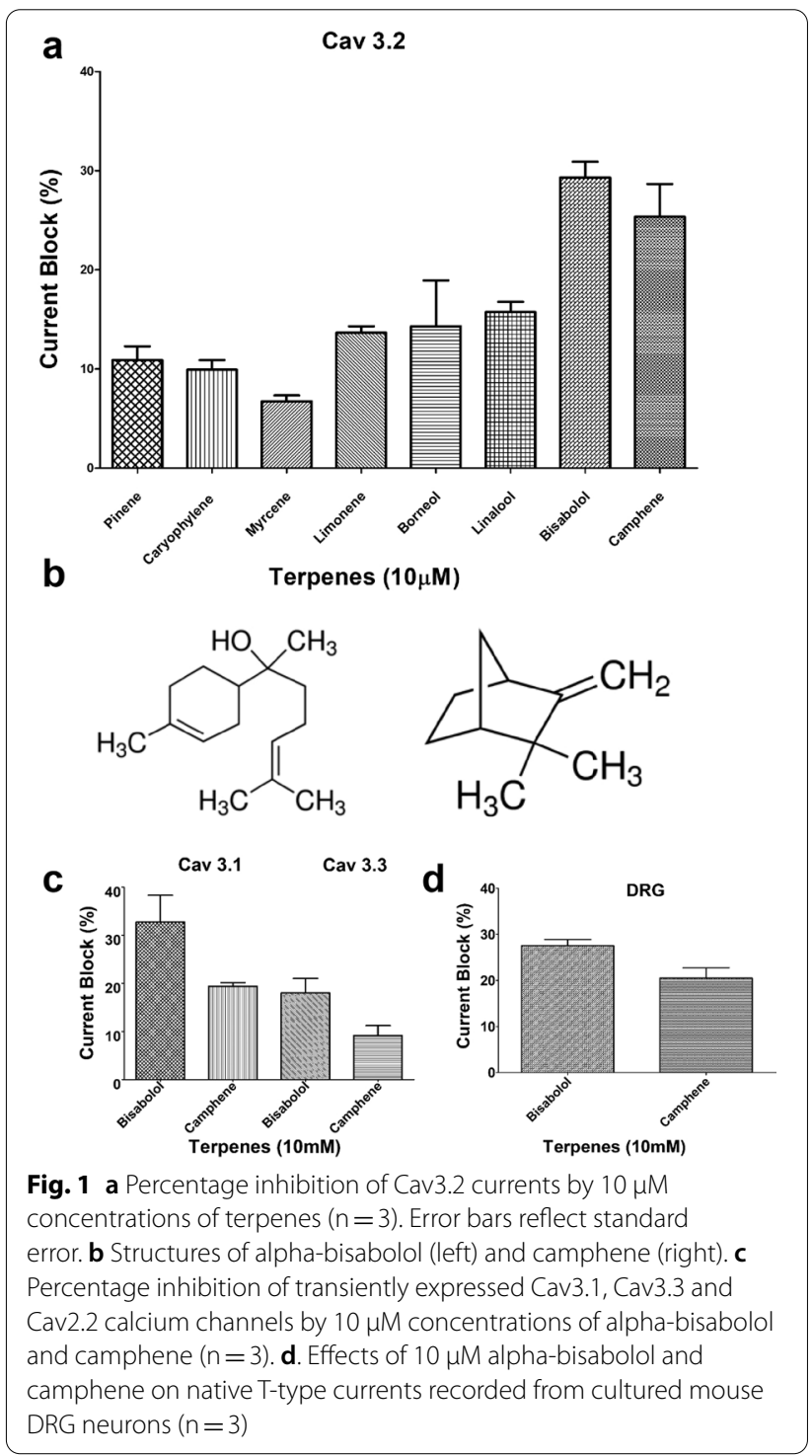


were performed by an EPC 10 amplifier linked to a personal computer equipped with Pulse (V8.65) software (HEKA Elektronik, Bellmore, NY). The recordings were performed when the cells became stable (at least $5 \mathrm{~min}$ after break in). The cells were first perfused with external solution to produce stable control currents. Then the cells were perfused with the terpenes dissolved in external solution. Currents were leak corrected with an online P/4 subtraction paradigm. In tsA-201 cells, Cav3.2 currents were elicited by depolarization from a holding potential of $-110 \mathrm{mV}$ to a test potential of $-20 \mathrm{mV}$ to $0 \mathrm{mV}$. Cav3.1 and Cav3.3 currents were elicited by depolarization from a holding potential of $-110 \mathrm{mV}$ to a test potential of $-20 \mathrm{mV}$. The duration of the test pulse was typically set as $200 \mathrm{~ms}$ and the inter-pulse interval was $20 \mathrm{~s}$. For DRG neuron recordings, the holding potential was $-90 \mathrm{mV}$ and the test depolarization was a $100 \mathrm{~ms}$ pulse to $-30 \mathrm{mV}$ to electrophysiologically isolate T-type currents. Data were recorded at $10 \mathrm{kHz}$ and filtered at $2.9 \mathrm{kHz}$. Data analysis and graph preparations were completed by GraphPad Prism 5 (GraphPad Software, La Jolla, CA). All electrophysiology data are given as mean values \pm standard errors.

\section{Animals}

Experiments were performed after approval of an animal protocol by the Institutional Animal Care and Use Committee and all efforts were made to minimize animal suffering according to the policies and recommendations of the International Association for the Study of Pain. We used male or female C57BL/6 J (wild-type) and male Cacna1h (Cav3.2 null, background C57BL/6 J) mice (mus musculus, 22-28 g, 7-8 weeks old) that were purchased from the Jackson Laboratory. Animals were housed at a maximum of five per cage $(30 \times 20 \times 15 \mathrm{~cm})$ and with free access to water and food. They were kept in controlled temperature of $23 \pm 1{ }^{\circ} \mathrm{C}$ on a $12 \mathrm{~h} \mathrm{light/dark} \mathrm{cycles} \mathrm{(lights}$ on at 7:00 a.m.) and all experiments were performed between 10 am and $3 \mathrm{pm}$. Different cohorts of mice were used for each test. The following compounds were used for in vivo studies: Complete Freund`s Adjuvant (CFA) and formalin (Sigma Chemical Company, St. Louis, MO, USA), camphene (Toronto Research Chemicals,Cat No. C165050) and alpha-bisabolol (Toronto Research Chemicals, Cat No. B399808). Mice received $10 \mu \mathrm{l}$ of camphene, alpha-bisabolol or vehicle intrathecally (i.t.). Appropriate vehicle (DMSO 5\% in PBS)-treated groups were assessed simultaneously.

\section{Formalin test}

Mice were acclimatized in the laboratory for at least $60 \mathrm{~min}$ before experiments. Animals received $20 \mu \mathrm{l}$ of a formalin solution (1.25\%) made up in PBS injected intraplantarily (i.pl.) in the ventral surface of the right hindpaw. Following i.pl. injections of formalin, the animals were immediately placed individually into observation chambers and the time spent licking or biting the injected paw was recorded and considered as a nociceptive response. We observed animals individually from 0 to $5 \mathrm{~min}$ (acute nociceptive phase) and $15-30 \mathrm{~min}$ (inflammatory phase) and the time spent licking or biting the injected paw was recorded with a chronometer. Camphene, alpha-bisabolol or vehicle were delivered intrathecally (20 min prior) and their actions on both nociceptive and inflammatory phases were evaluated.

\section{Persistent inflammatory pain induced by CFA}

To induce hyperalgesia produced by peripheral inflammation, $20 \mu \mathrm{l}$ of Complete Freund's Adjuvant (CFA) was injected subcutaneously in the plantar surface of the right hindpaw (i.pl.) [33]. Sham groups received $20 \mu \mathrm{l}$ of PBS in the ipsilateral paw. Animals were treated with camphene (3 $\mu \mathrm{g} /$ i.t. $)$, alpha-bisabolol $(1 \mu \mathrm{g} /$ i.t. $)$, or vehicle $(10 \mu \mathrm{l} / \mathrm{i.t.}$. $)$ and 3 days following CFA injection they had their thermal withdrawal latency threshold tested.

\section{Mononeuropathy caused by partial sciatic nerve injury}

To induce neuropathic pain in mice, a partial ligation of the sciatic nerve (PSNI) was performed according to Malmberg and Basbaum [34]. Using isoflurane anesthesia and in aseptic conditions the right sciatic nerve was exposed at high-thigh level and a 6-0 silk suture was inserted into the nerve and tightly ligated so that the dorsal $1 / 3-1 / 2$ of the nerve thickness was trapped in the ligature and the wound was closed with 4-0 silk suture. In all mice the left (contralateral) leg and sciatic nerve were untouched, and in sham operated mice the nerve was left intact. Twenty-one days later the animals received camphene $(3 \mu \mathrm{g} / \mathrm{i}$.t. $)$, alpha-bisabolol $(1 \mu \mathrm{g} / \mathrm{i}$.t. $)$, or vehicle $(10 \mu l / i . t$. of PBS). Measurements of mechanical withdrawal thresholds were taken as described below.

\section{Assessment of thermal and mechanical hypersensitivity}

Thermal hyperalgesia of CFA-injected animals was examined by measuring the latency to withdrawal of right hind paws on a focused beam of radiant heat $(I R=30)$ of a Plantar Test apparatus (UgoBasile, Varese, Italy). Animals were placed individually in a small enclosed testing arena $(20 \mathrm{~cm} \times 18.5 \mathrm{~cm} \times 13 \mathrm{~cm}$, length $\times$ width $\times$ height $)$ on top of a wire mesh floor. Mice were allowed to acclimate for a period of at least $90 \mathrm{~min}$. The device was positioned beneath the animal, so that the radiant heat was directly under the plantar surface of the ipsilateral hind paw. Three trials for each mouse were performed. The apparatus was set at a cut-off time of $30 \mathrm{~s}$ to avoid tissue 
damage. Thermal hyperalgesia was evaluated immediately prior to the treatments (Time 0 ) and 15, 45, 90 and 180 min after treatment when mice were between 14 and 17 weeks old.

For evaluation of mechanical hyperalgesia of neuropathic mice, we used a digital plantar aesthesiometer (DPA, UgoBasile, Varese, Italy). Mice were placed individually in a small enclosed testing arena $(20 \mathrm{~cm} \times 18.5 \mathrm{~cm} \times 13 \mathrm{~cm}$, length $\times$ width $\times$ height $)$ on top of a grid floor while they acclimated in the experimental room for a period of at least $90 \mathrm{~min}$ before the measurements. The aesthesiometer was positioned underneath the animal with the filament directly under the plantar surface of the ipsilateral hind paw. To verify the time-dependence effect of camphene or alpha bisabolol, mechanical withdrawal thresholds were determined at 1 day prior to CFA injection (Baseline), and 3 days after CFA injection at $0,45,90$ and 180 min after treatment of mice with either camphene or alpha-bisabolol. Each paw was tested three times per session.

\section{Intrathecal drug treatment}

Intrathecal injections were performed in fully conscious mice as previously described [35] and as routinely performed in our lab [36]. Mice were manually restrained, the dorsal fur of each mouse was shaved, the spinal column was arched, and a 30-gauge needle attached to a 25- $\mu$ l Hamilton microsyringe (Hamilton, Birmingham, UK) was inserted into the subdural space between the $L_{4}$ and $L_{5}$ vertebrae. Accurate positioning of the needle tip was confirmed by a characteristic tail-flick response of animal when the needle if correctly positioned. Intrathecal injections of $10 \mu \mathrm{l}$ were delivered over a period of $5 \mathrm{~s}$.

\section{Statistical analysis}

For in vivo experiments, data are presented as means \pm SEM and evaluated by one-way, two-way or three-way analysis of variance (ANOVA) followed by a Tukey's test. A value of $\mathrm{P}<0.05$ was considered to be sig-

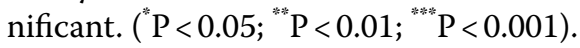

\section{Results}

\section{Cannabis derived terpenes inhibit Cav3.2 channels}

We tested the inhibitory actions of eight commercially available terpenes on human Cav3.2 calcium channels transiently expressed in tsA-201 cells using whole cell patch clamp. At a testing concentration of $10 \mu \mathrm{M}$, six out of the eight tested terpenes (pinene, caryophylene, myrcene, limonene, borneol and lanalool mediated less than 15 percent inhibition (Fig. 1a). In contrast, alphabisabolol (Fig. 1b, left) and camphene (Fig. 1b, right) were twice as effective (29.3\% and $25.4 \%$ inhibition, repectively). Camphene and alpha-bisabolol were tested on transiently expressed Cav3.1 and Cav3.3 T-type channels (Fig. 1c), revealing that these terpenes block all of these channels, albeit to varying extent with Cav3.3 being the least affected. Finally, we examined the effects of these two terpenes on native T-type currents in cultured mouse DRG neurons, revealing a similar inhibition as that seen with transiently expressed channels (Fig. 1d).

Figure 2a and $\mathrm{b}$ depict dose response curves for alphabisabolol and camphene inhibition of Cav3.2, indicating that block by these two compounds is partial, with a pleateau of about 30 percent maxiumum inhibition. The $\mathrm{IC}_{50}$ values obtained from the dose response curves were $4.5 \pm 1.1 \mu \mathrm{M}$ for alpha-bisabolol, and $7.7 \pm 1.8 \mu \mathrm{M}$ for camphene. Neither compound mediated a significant effect on the voltage-dependence of activation as evident from the current voltage-relations shown in Fig. 2c and $\mathrm{d}$. Bisabalol and to a smaller extent camphene shifted the steady state inactivation curves towards more hyperpolarized potentials (by $6 \mathrm{mV}$ and $4.5 \mathrm{mV}$, repectively), thus leading to additional inhibitory effects at typical neuronal resting membrane potentials (Fig. 2e, f). For purposes of comparison, we also examined the effects of the phytocannabinoid THC on transiently expressed Cav3.2 channels under the same experimental conditions. As shown in Additional file 1: Fig. S1, THC potently and completely inhibited Cav3.2 channel activity, and like the terpenes, caused a hyperpolarizing shift in the half inactivation potential (Additional file 1: Fig. S1) in line what was reported for this compound previously [28].

Altogether, these data indicate that alpha-bisabalol and camphene are capable of inhibiting recombinant Cav3.2 channels, with bisabalol being more effective.

\section{Camphene and alpha-bisabolol inhibit inflammatory pain and neuropathic pain}

To ascertain putative in vivo effects of camphene and bisabolol, we first examined their analgesic actions in the formalin test, a model of acute inflammatory pain. Mice received an intraplantar injection of formalin, leading to two distinct phases of nocifensive responses that are characterized by licking and biting of the affected paw. As shown in Fig. 3a-d, camphene and alpha-bisabolol (when delivered intrathecally) reduced the nocifensive response time in both phases in a dose-dependent manner, with bisabolol exerting its effects at a three fold lower dose (in $\mu \mathrm{g}$ ) compared to camphene (note that the molecular weight of bisabolol is about $60 \%$ greater). Next, we tested the effects of both compounds in a chronic inflammatory pain model based on intraplantar injection of Complete Freund's Adjuvant (CFA). In male mice, CFA injection resulted in a marked reduction in paw withdrawal latency in response to radiant heat (Fig. 4a). When delivered 

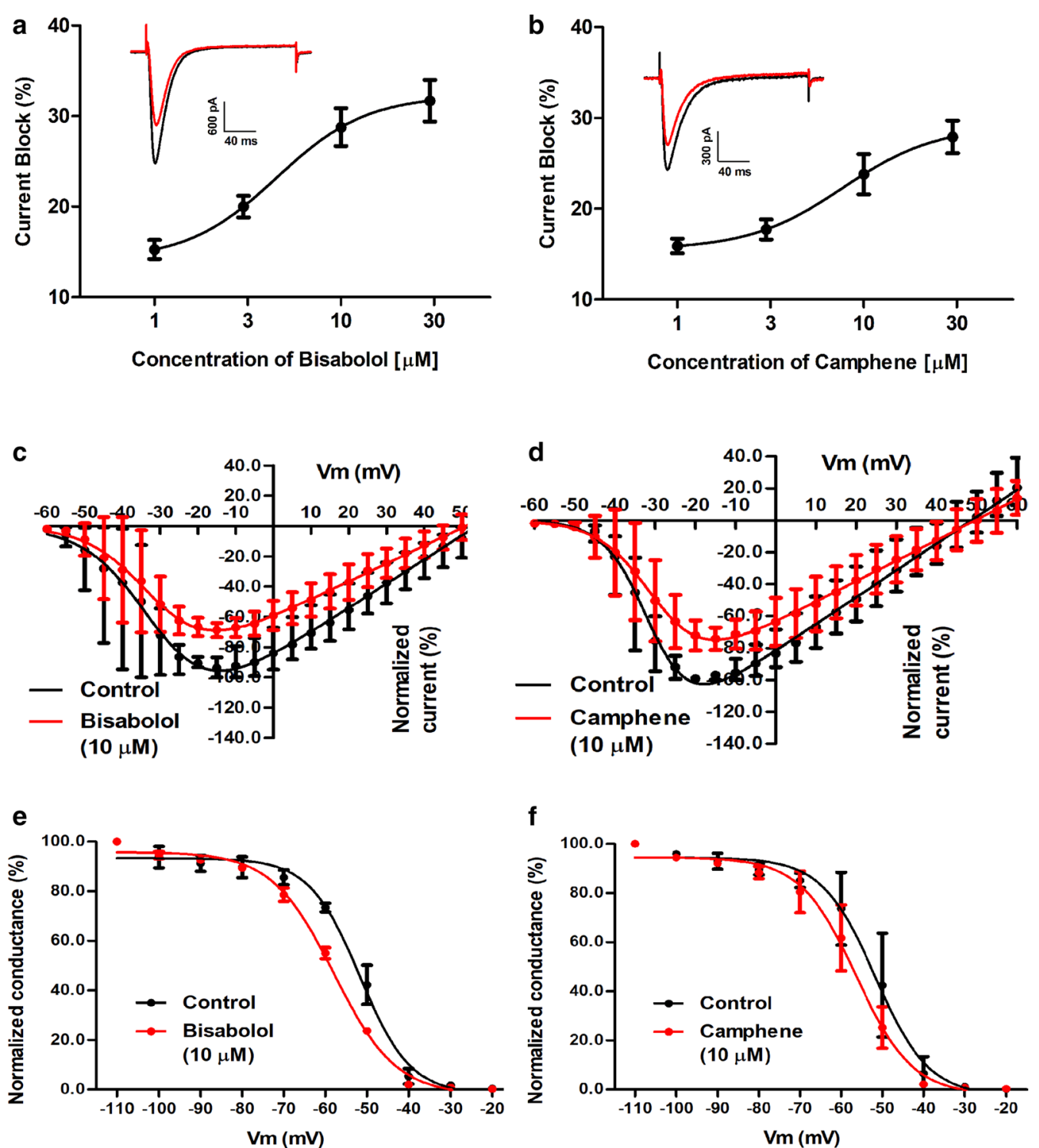

Fig. 2 a Dose-response relation for alpha-bisabolol inhibition of Cav3.2 channels expressed in tsA-201 cells. The IC 50 obtained from the fit was $4.52 \pm 1.08 \mu \mathrm{M}(\mathrm{n}=3$ per dose). The insert shows a representative current before and after the application of $10 \mu \mathrm{M}$ of alpha-bisabolol. $\mathbf{b}$ Dose-response relation for camphene inhibition of Cav3.2. The $I_{50}$ obtained from the fit was $7.73 \pm 1.75 \mu \mathrm{M}(\mathrm{n}=3$ per dose). The insert shows a representative current before and after the application of $10 \mu \mathrm{M}$ of camphene. $\mathbf{c}$ Effect of alpha-bisabolol on the current-voltage relation of Cav3.2. The half activation potentials obtained from the fitted curves were $-30.7 \pm 1.9 \mathrm{mV}$ and $-31.2 \pm 1.8 \mathrm{mV}$ before and after the application of alpha-bisabolol, respectively $(10 \mu \mathrm{M}, \mathrm{n}=3, \mathrm{p}=0.96$, Paired $t$ test). $\mathbf{d}$ Effect of camphene on the current-voltage relation of Cav3.2. The half activation potentials obtained from the fitted curves were $-30.9 \pm 0.9 \mathrm{mV}$ and $-29.5 \pm 1.5 \mathrm{mV}$ before and after the application of camphene, respectively $(10 \mu \mathrm{M}, \mathrm{n}=3, \mathrm{p}=0.70$, Paired $t$ test). e Effect of alpha-bisabolol on the steady-state inactivation curve of Cav3.2. The half-inactivation potentials from the fitted curves were $-51.7 \pm 0.7 \mathrm{mV}$ and $-57.9 \pm 0.4 \mathrm{mV}$ before and after the application of alpha-bisabolol $(10 \mu \mathrm{M}, \mathrm{n}=3, \mathrm{p}=0.02$, Paired $t$ test). $\mathbf{f}$ Effect of camphene on the steady-state inactivation curve of Cav3.2. The half-inactivation potentials from the fitted curves were $-51.7 \pm 1.3 \mathrm{mV}$ and $-56.3 \pm 0.9 \mathrm{mV}$ before and after the application of camphene $(10 \mu \mathrm{M}, \mathrm{n}=3, \mathrm{p}=0.04$, Paired $t$ test $)$

intrathecally, both terpenes increased withdrawal latencies. This effect subsided about 90 min after injection, and was fully reversed at a time point of three hours (Fig. 4a). To determine whether the effects of the two compounds involved an action on Cav3.2 channels, we performed analogous experiments in Cav3.2 null mice. These mice have compensatory mechanisms that allow them to exhibit CFA-induced hypernociception, even though Cav3.2 channels are absent [4]. As shown in Fig. 4b and c, eliminating the putative physiological 

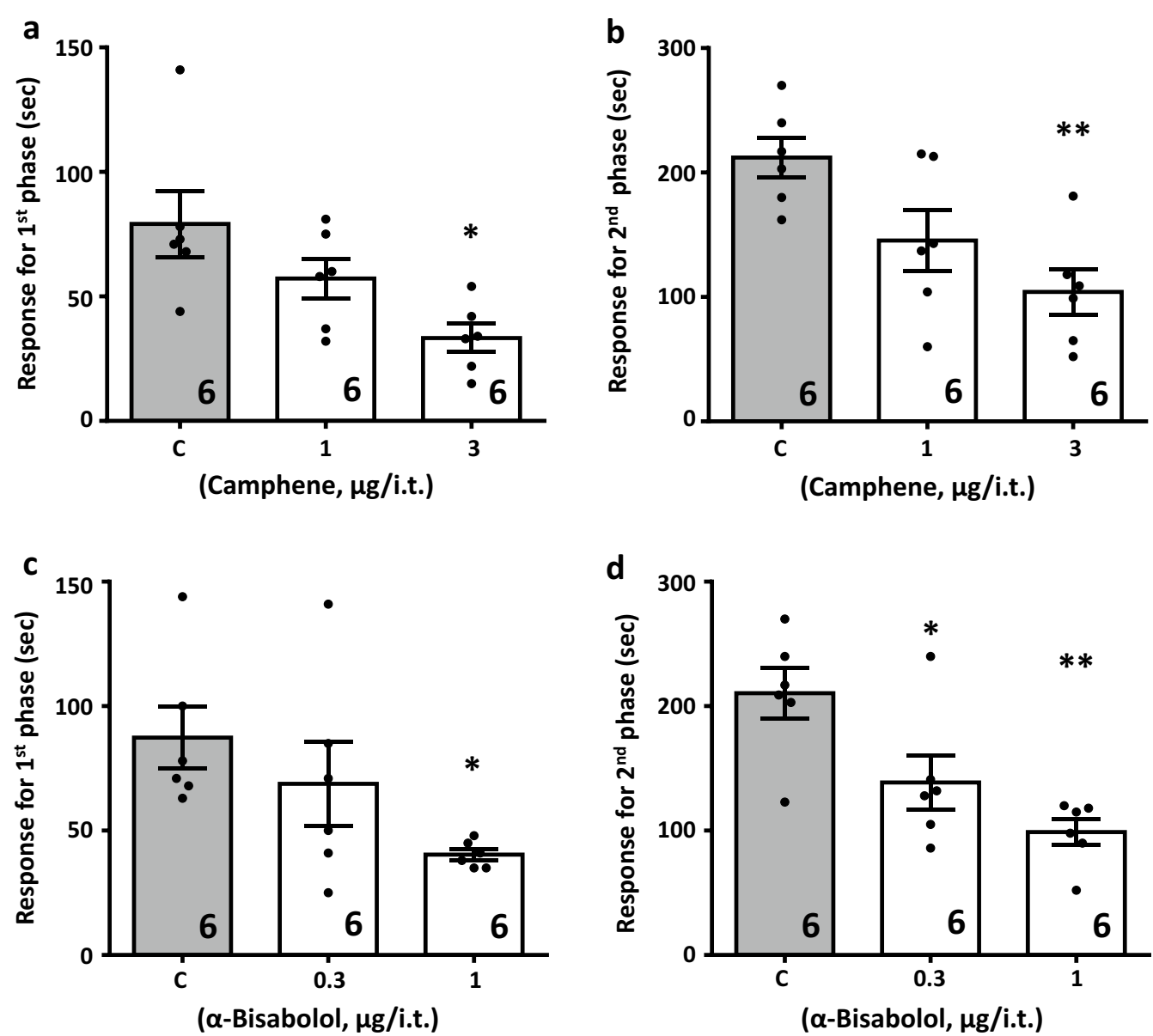

Fig. 3 Effect of increasing doses of intrathecal camphene ( $\mathbf{a}$ and $\mathbf{b}$ ) and alpha-bisabolol (c and $\mathbf{d}$ ) on the first and second phases of formalin-induced pain. Asterisks denote the significance relative to the control group ( ${ }^{*} \mathrm{P}<0.05$, ${ }^{*} \mathrm{P}<0.01$, one-way ANOVA followed by Tukey's test)

target eliminated the analgesic effects of camphene and alpha-bisabolol, thus confirming that Cav3.2 channels are required for the in vivo actions of the two terpenes, despite the fact that these compounds inhibit other types of Cav3 channels (see Fig. 1c). There is a large body of evidence supporting sex differences in various aspects of pain signaling [37-40]. To determine if the effects of the two terpenes were subject to sexual dimorphisms, we examined them in a cohort of female mice. As shown in Fig. 5, both camphene and alpha-bisabolol were effective in reducing thermal hypersensitivity in the CFA model, thus indicating that their effects are sex independent.

To examine whether the two terpenes are effective in neuropathic pain states, we tested them in a mouse model of partial sciatic nerve injury which results in long lasting mechanical hypersensitivity. Injury to the sciatic nerve triggered a robust reduction in mechanical withdrawal threshold that was partially reversed upon intrathecal delivery of camphene or alpha-bisabolol (Fig. 6).
Altogether, these data show that the two terpense examined here have robust effects in mouse models of inflammatory and neuropathic pain.

\section{Discussion}

Natural compounds found in cannabis have been associated with antinociceptive effects [41], most notably for phytocannabinoids such as THC and CBD $[15,18,19]$. Analgesic effects have also been reported for several terpenes. For example, systemic (oral) alpha-bisabolol showed efficacy in a model of visceral inflammation, in the second phase of the formalin test in mice, and in carrageenan induced inflammation [42] (see also [43]). The authors concluded that its effect was mediated by an antiinflammatory action, rather than an effect on the nervous system. This contrasts with our findings with intrathecal delivery which required T-type channels as a target and most likely an action on neurons. Systemically delivered camphene has also been associated with antinociceptive activity in acetic acid induced writhing behavior, and 
a
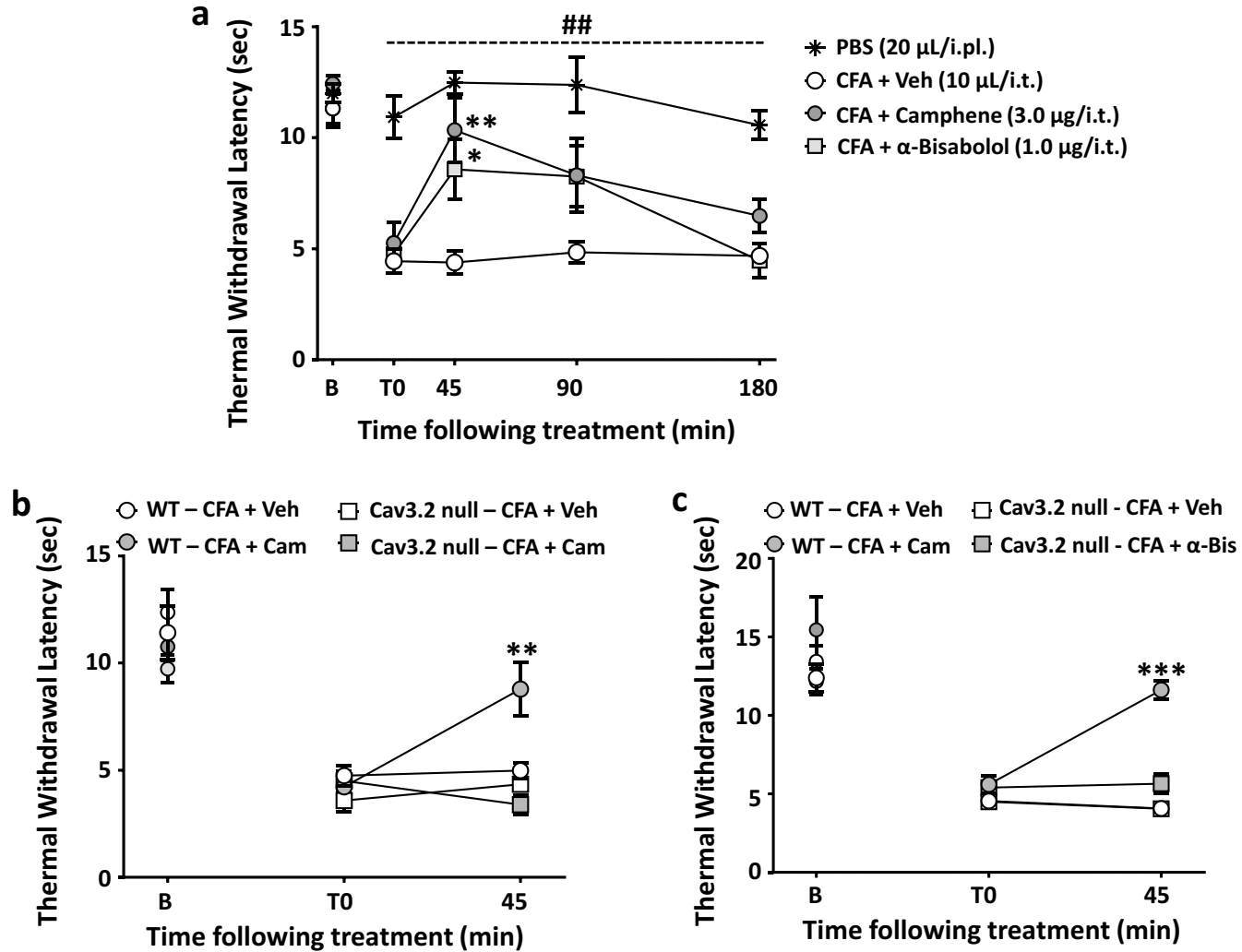

Fig. 4 a Thermal withdrawal latencies of CFA-injected male mice treated with camphene (3.0 $\mu \mathrm{g} / \mathrm{i}$.t.), alpha-bisabolol (1.0 $\mu \mathrm{g} / \mathrm{i}$.t.) or control vehicle (10 ul/i.t). The dashed line and hashtag indicate the range of data points where PBS treated animals differed from the CFA treated group (\#\# $\mathrm{P}<0.01)$. b, c Data for thermal hyperalgesia of Cav3.2 null and WT mice when measured $45 \mathrm{~min}$ after treatment with $\mathbf{b}$ camphene (3.0 $\mu \mathrm{g} / \mathrm{i}$.t.) or $\mathbf{c}$ alpha-bisabolol (1.0 $\mu \mathrm{g} / \mathrm{it.t}$.$) . Each circle represents the mean \pm$ S.E.M. $(n=4-9)$ and data are representative of 2 independent sets of experiments. Statistical analyses were performed by two-way, or three-way ANOVA followed by Tukey's test ${ }^{*} \mathrm{P}<0.05,{ }^{*} \mathrm{P}<0.01$ relative to vehicle)
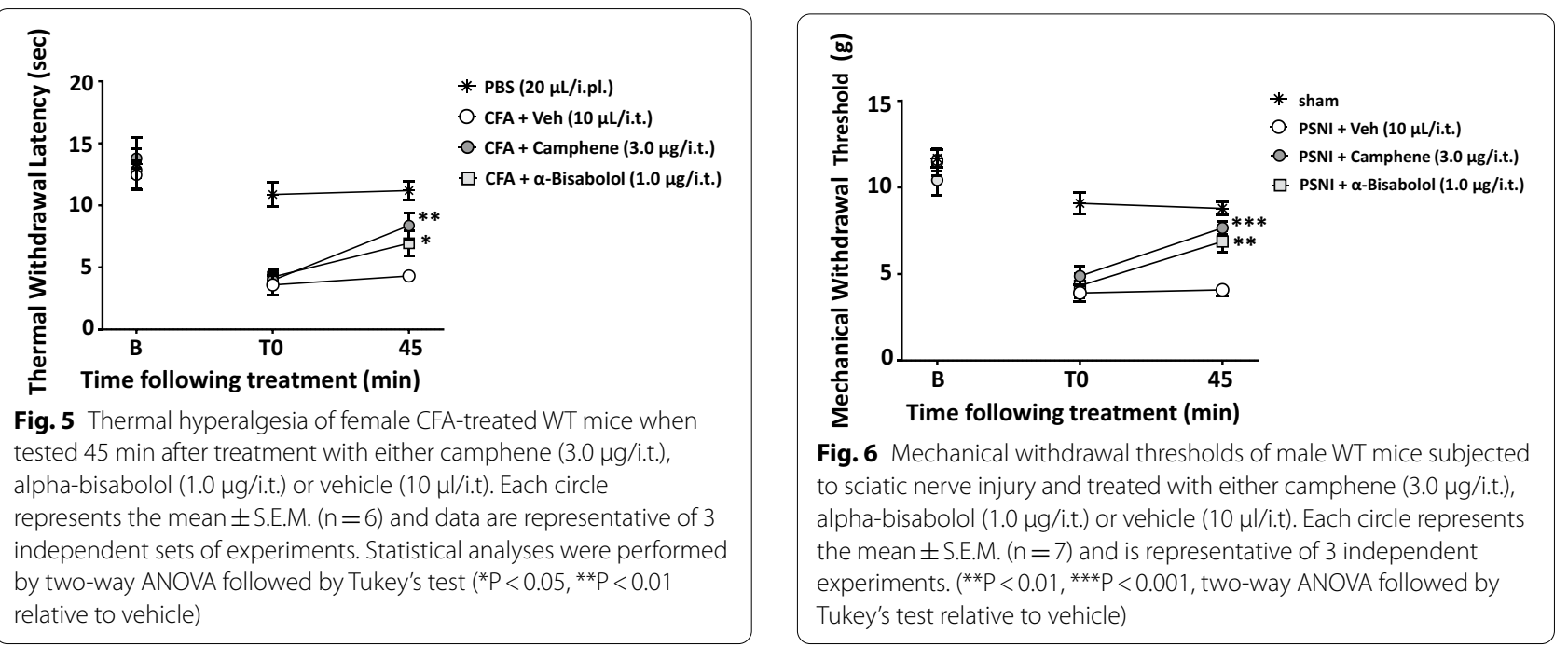
in the formalin test [44], in agreement with our work. We also note that borneol (one of the compounds that showed poor activity at inhibiting Cav3.2 in our study) mediated analgesic effects in chronic inflammatory and neuropathic pain models in mice [45]. Along these lines, linalool has has been shown to mediate antihyperalgesic activity in a mouse model of fibromyalgia [46]. It is unclear whether these effects involve T-type calcium channels, however, a previous report that showed that linalool reduces neuronal excitability via inhibition of sodium channels [47].

The two compounds studied here have been shown to be present in a variety of cannabis plants and cannabis derived products such as essential oils and bubble gum, including a bisabalool dominant bubble gum version [48]. Alpha-bisabolol and camphene are among the top 20 most abundant tepenes found in 240 different cannabis cultivars of C. sativa flower, although typically of much lower abundance than for example myrcene, beta-caryophyllene or d-limonene [49]. Because many other terpenes are found in these cultivars and extracts [48, 49], it is difficult to correlate and biological effects with specific types of terpenes found in these types of products. Many terpenes are able to cross the blood brain barrier $[50,51]$, and hence it is unclear whether the systemic effects described in the above studies are mediated by CNS or peripheral actions. In our study, camphene and alpha-bisabolol were delivered exclusively via the intrathecal route, making it highly unlikely that their actions occurred at the level of the brain, as opposed to inhibiting T-type channel activity either in spinal cord neurons, or at nerve endings of primary afferent fibers. Our data with Cav3.2 null mice clearly indicate that the analgesic properties of spinally delivered terpenes required an action on Cav3.2 channels which are known to be expressed in specific afferents and in the spinal cord $[5,6]$.

In our hands, in contrast with THC, the effects of both terpenes were partial, with a plateau of just over 30\% inhibition of Cav3.2 channels at a holding potential of - $100 \mathrm{mV}$. Additional inhibition could be observed due to a small, but significant shift in half-inacivation potential, leading to reduced availablity of channel opening at more depolarized resting membrane potentials. Is is unclear why the inhibitory effects are partial. Possiblities include partial occlusion of the pore of the channel, or an allosteric effect that may result in a reduction in the maximum open probability of the channel without affcting permeation. Irrespective of how the compounds inhibit the function of the channel at the molecular level, the combined effects of resting channel block and the effect on the voltage-dependence of inactivation culminate in aproximately $50 \%$ inhibition of channel activity at saturating doses. Assuming that native channels behave similarly to those expressed in tsA-201 cells, such a reduction in overall Cav3.2 activity should be sufficient to account for the observed analgesic effects.

\section{Conclusions}

In summary, we report a Cav3.2 channel dependent analgesic effect of two terpenes that are present in cannabis plants. To what extent this contributes to cannabis mediated analgesia needs to be explored further.

Abbreviations

THC: Delta(9)-tetrahydrocannabinol; CBD: Cannabidiol; CFA: Complete Freund's adjuvant; PBS: Phosphate buffered saline; DRG: Dorsal root ganglion.

\section{Supplementary Information}

The online version contains supplementary material available at https://doi. org/10.1186/s13041-021-00876-6.

Additional file 1: Fig. S1. Effect of THC on Cav3.2 calcium channels. Dose response curve for THC block of Cav3.2 channels, and effect of THC on activation and inactivation of the channels.

\section{Acknowledgements}

We thank Mrs. Lina Chen for technical support. We thank Dr. Sunil Rajput for helpful suggestions.

\section{Authors' contributions}

SH performed electrophysiological recordings, VMG performed in vivo studies. GWZ conceived and supervised the study. GWZ wrote the manuscript. All authors read and approved the final manuscript.

\section{Funding}

This work was supported by grants to GWZ from Alberta Innovates and the Canadian Institutes of Health Research. GWZ holds a Canada Research Chair.

Availability of data and materials

All data generated or analysed during this study are included in this published article.

\section{Declarations}

Ethics approval and consent to participate

This study was approved by the University of Calgary's animal care committee.

\section{Consent for publication}

Not applicable.

\section{Competing interests}

The authors declare no competing interest.

Received: 6 September 2021 Accepted: 3 November 2021

Published online: 14 November 2021

\section{References}

1. Waxman SG, Zamponi GW. Regulating excitability of peripheral afferents: emerging ion channel targets. Nat Neurosci. 2014;17(2):153-63.

2. Bourinet $\mathrm{E}$, Altier $\mathrm{C}$, Hildebrand ME, Trang T, Salter MW, Zamponi GW. Calcium-permeable ion channels in pain signaling. Physiol Rev. 2014;94(1):81-140.

3. Jacus MO, Uebele VN, Renger JJ, Todorovic SM. Presynaptic Cav3.2 channels regulate excitatory neurotransmission in nociceptive dorsal horn 
neurons. J Neurosci. 2012;32(27):9374-82. https://doi.org/10.1523/JNEUR OSCI.0068-12.2012.

4. García-Caballero A, Gadotti VM, Stemkowski P, Weiss N, Souza IA, Hodgkinson $V$, et al. The deubiquitinating enzyme USP5 modulates neuropathic and inflammatory pain by enhancing Cav3.2 channel activity. Neuron. 2014;83(5):1144-58. https://doi.org/10.1016/j.neuron.2014.07. 036.

5. Candelas $M$, Reynders A, Arango-Lievano M, Neumayer C, Fruquière A, Demes E, et al. Cav3.2 T-type calcium channels shape electrical firing in mouse Lamina II neurons. Sci Rep. 2019;9(1):3112. https://doi.org/10. 1038/s41598-019-39703-3.

6. François A, Schüetter N, Laffray S, Sanguesa J, Pizzoccaro A, Dubel S, et al. The low-threshold calcium channel Cav3.2 determines low-threshold mechanoreceptor function. Cell Rep. 2015;10(3):370-82. https://doi.org/ 10.1016/j.celrep.2014.12.042.

7. Lauzadis J, Liu H, Lu Y, Rebecchi MJ, Kaczocha M, Puopolo M. Contribution of t-type calcium channels to spinal cord injury-induced hyperexcitability of nociceptors. J Neurosci. 2020;40(38):7229-40. https://doi.org/10.1523/ JNEUROSCI.0517-20.2020.

8. Jagodic MM, Pathirathna S, Nelson MT, Mancuso S, Joksovic PM, Rosenberg ER, et al. Cell-specific alterations of T-type calcium current in painful diabetic neuropathy enhance excitability of sensory neurons. J Neurosci. 2007;27(12):3305-16. https://doi.org/10.1523/JNEUROSCI.4866-06.2007.

9. Wen XJ, Xu SY, Chen ZX, Yang CX, Liang H, Li H. The roles of T-type calcium channel in the development of neuropathic pain following chronic compression of rat dorsal root ganglia. Pharmacology. 2010;85(5):295300. https://doi.org/10.1159/000276981.

10. Tomita S, Sekiguchi F, Kasanami Y, Naoe K, Tsubota M, Wake H, et al. Cav3.2 overexpression in $L 4$ dorsal root ganglion neurons after $L 5$ spinal nerve cutting involves Egr-1, USP5 and HMGB1 in rats: An emerging signaling pathway for neuropathic pain. Eur J Pharmacol. 2020;888: 173587. https://doi.org/10.1016/j.ejphar.2020.173587.

11. Joksimovic SL, Joksimovic SM, Tesic V, García-Caballero A, Feseha S, Zamponi GW, et al. Selective inhibition of CaV3.2 channels reverses hyperexcitability of peripheral nociceptors and alleviates postsurgical pain. Sci Signal. 2018. https://doi.org/10.1126/scisignal.aao4425.

12. Marger F, Gelot A, Alloui A, Matricon J, Ferrer JF, Barrère C, et al. T-type calcium channels contribute to colonic hypersensitivity in a rat model of irritable bowel syndrome. Proc Natl Acad Sci U S A. 2011;108(27):1126873. https://doi.org/10.1073/pnas.1100869108.

13. Snutch TP, Zamponi GW. Recent advances in the development of T-type calcium channel blockers for pain intervention. Br J Pharmacol. 2018;175(12):2375-83. https://doi.org/10.1111/bph.13906.

14. Bourinet E, Alloui A, Monteil A, Barrère C, Couette B, Poirot O, et al. Silencing of the Cav3.2 T-type calcium channel gene in sensory neurons demonstrates its major role in nociception. EMBO J. 2005;24(2):315-24. https://doi.org/10.1038/sj.emboj.7600515.

15. Naef M, Curatolo M, Petersen-Felix S, Arendt-Nielsen L, Zbinden A, Brenneisen $R$. The analgesic effect of oral delta-9-tetrahydrocannabinol (THC), morphine, and a THC-morphine combination in healthy subjects under experimental pain conditions. Pain. 2003;105(1-2):79-88.

16. Whiteside GT, Lee GP, Valenzanom KJ. The role of the cannabinoid CB2 receptor in pain transmission and therapeutic potential of small molecule CB2 receptor agonists. Curr Med Chem. 2007;14(8):917-36.

17. Anand P, Whiteside G, Fowler CJ, Hohmann AG. Targeting CB2 receptors and the endocannabinoid system for the treatment of pain. Brain Res Rev. 2009;60:255-66.

18. Casey SL, Atwal N, Vaughan CW. Cannabis constituent synergy in a mouse neuropathic pain model. Pain. 2017;158(12):2452-60.

19. Lee G, Grovey B, Furnish T, Wallace M. Medical cannabis for neuropathic pain. Curr Pain Headache Rep. 2018;22(1):8.

20. Watkins AR. Cannabinoid interactions with ion channels and receptors. Channels (Austin). 2019;13(1):162-7.

21. Jansen C, Shimoda LMN, Kawakami JK, Ang L, Bacani AJ, Baker JD, et al. Myrcene and terpene regulation of TRPV1. Channels (Austin). 2019;13(1):344-66.

22. Starkus J, Jansen C, Shimoda LMN, Stokes AJ, Small-Howard AL, Turner H. Diverse TRPV1 responses to cannabinoids. Channels (Austin). 2019;13(1):172-91.

23. Berger ND, Gadotti VM, Petrov RR, Chapman K, Diaz P, Zamponi GW. NMP-7 inhibits chronic inflammatory and neuropathic pain via block of
Cav3.2 T-type calcium channels and activation of CB2 receptors. Mol Pain. 2014;10:77. https://doi.org/10.1186/1744-8069-10-77.

24. You H, Gadotti VM, Petrov RR, Zamponi GW, Diaz P. Functional characterization and analgesic effects of mixed cannabinoid receptor/T-type channel ligands. Mol Pain. 2011;7:89. https://doi.org/10.1186/1744-8069-7-89.

25. Chemin J, Monteil A, Perez-Reyes E, Nargeot J, Lory P. Direct inhibition of T-type calcium channels by the endogenous cannabinoid anandamide. EMBO J. 2001;20(24):7033-40. https://doi.org/10.1093/emboj/20.24.7033.

26. Ross HR, Gilmore AJ, Connor M. Inhibition of human recombinant T-type calcium channels by the endocannabinoid $\mathrm{N}$-arachidonoyl dopamine. Br J Pharmacol. 2009;156(5):740-50. https://doi.org/10.1111/j.1476-5381. 2008.00072.x

27. Barbara G, Alloui A, Nargeot J, Lory P, Eschalier A, Bourinet E, et al. T-type calcium channel inhibition underlies the analgesic effects of the endogenous lipoamino acids. J Neurosci. 2009;29(42):13106-14. https://doi.org/ 10.1523/JNEUROSCI.2919-09.2009.

28. Ross HR, Napier I, Connor M. Inhibition of recombinant human T-type calcium channels by Delta9-tetrahydrocannabinol and cannabidiol. J Biol Chem. 2008;283(23):16124-34.

29. Sommano SR, Chittasupho C, Ruksiriwanich W, Jantrawut P. The cannabis terpenes. Molecules. 2020;25(24):5792. https://doi.org/10.3390/molec ules25245792.

30. Ferber SG, Namdar D, Hen-Shoval D, Eger G, Koltai H, Shoval G, Shbiro L, Weller A. The "entourage effect": terpenes coupled with cannabinoids for the treatment of mood disorders and anxiety disorders. Curr Neuropharmacol. 2020;18:87-96.

31. Stringer RN, Jurkovicova-Tarabova B, Huang S, Haji-Ghassemi O, Idoux R, Liashenko A, Souza IA, Rzhepetskyy Y, Lacinova L, Van Petegem F, Zamponi GW, Pamphlett R, Weiss N. A rare CACNA1H variant associated with amyotrophic lateral sclerosis causes complete loss of Ca v 3.2 T-type channel activity. Mol Brain. 2020;13(1):33. https://doi.org/10.1186/ s13041-020-00577-6.

32. Altier $\mathrm{C}$, Khosravani $\mathrm{H}$, Evans RM, Hameed $\mathrm{S}$, Peloquin JB, Vartian B, Chen L, Beedle AM, Ferguson SG, Mezghrani A, Dubel SJ, Bourinet E, McRory JE, Zamponi GW. ORL1 receptor mediated internalization of N-type calcium channels. Nat Neurosci. 2006;9:31-40.

33. Ferreira J, Campos MM, Pesquero JB, Araújo RC, Bader M, Calixto JB. Evidence for the participation of kinins in Freund's adjuvant-induced inflammatory and nociceptive responses in kinin B1 and B2 receptor knockout mice. Neuropharmacol. 2001;41:1006-12.

34. Malmberg A, Basbaum A. Partial sciatic nerve injury in the mouse as a model of neuropathic pain: behavioral and neuroanatomical correlates. Pain. 1998;76:215-22.

35. Hylden JL, Wilcox GL. Intrathecal morphine in mice: a new technique. Eur J Pharmacol. 1980;67:313-6.

36. Huang J, Gadotti VM, Chen L, Souza IA, Huang S, Wang D, et al. A neuronal circuit for activating descending modulation of neuropathic pain. Nat Neurosci. 2019;22:1659-68.

37. Sorge RE, Mapplebeck JCS, Rosen S, Beggs S, Taves S, Alexander JA, et al. Different immune cells mediate mechanical pain hypersensitivity in male and female mice. Nat Neurosci. 2015;18:1081-3.

38. Halievski K, Ghazisaeidi S, Salter MW. Sex-dependent mechanisms of chronic pain: a focus on microglia and P2X4R. J Pharmacol Exp Ther. 2020;375:202-9.

39. Tonsfeldt KJ, Suchland KL, Beeson KA, Lowe JD, Li MH, Ingram SL. Sex differences in GABAA signaling in the periaqueductal gray induced by persistent inflammation. J Neurosci. 2016;36:1669-81.

40. Jones AF, Sheets PL. Sex-Specific disruption of distinct mPFC inhibitory neurons in spared-nerve injury model of neuropathic pain. Cell Rep. 2020. https://doi.org/10.1016/i.celrep.2020.107729.

41. Hill KP, Palastro MD, Johnson B, Ditre JW. Cannabis and pain: a clinical review. Cannabis Cannabinoid Res. 2017;2(1):96-104.

42. Rocha NFM, Rios ERV, Carvalho AMR, Cerqueria GS, Lopes AA, Leial LKAM, et al. Anti-nociceptive and anti-inflammatory activities of (-)-a-bisabolol in rodents. Naunyn Schmiedebergs Arch Pharmacol. 2011;384(6):525-33.

43. Leite GdO, Leite LH, Sampaio RS, Araruna MK, deMenezes IR, da Costa JG, Campos AR. (-)-a-Bisabolol attenuates visceral nociception and inflammation in mice. Fitoterapia. 2011;82(2):208-11.

44. Quintans-Júnior L, Moreira JC, Pasquali MA, Rabie SM, Pires AS, Schröder $\mathrm{R}$, et al. Antinociceptive activity and redox profile of the monoterpenes 
(+)-camphene, $\mathrm{p}$-cymene, and geranyl acetate in experimental models. ISRN Toxicol. 2013;2013: 459530.

45. Jiang J, Shen YY, Li J, Lin YH, Luo CX, Zhu DY. (+)-Borneol alleviates mechanical hyperalgesia in models of chronic inflammatory and neuropathic pain in mice. Eur J Pharmacol. 2015;757:53-8.

46. Nascimento SS, Camargo EA, DeSantana JM, Araújo AA, Menezes PP, Lucca-Júnior W, et al. Linalool and linalool complexed in $\beta$-cyclodextrin produce anti-hyperalgesic activity and increase Fos protein expression in animal model for fibromyalgia. Naunyn Schmiedebergs Arch Pharmacol. 2014;387(10):935-42.

47. Leal-Cardoso JH, da Silva-Alves KS, Ferreira-da-Silva FW, dos SantosNascimento T, Joca HC, de Macedo FH, et al. Linalool blocks excitability in peripheral nerves and voltage-dependent $\mathrm{Na}+$ current in dissociated dorsal root ganglia neurons. Eur J Pharmacol. 2010;645(13):86-93.

48. Hanus LO, Hod Y. Terpenes/terpenoids in cannabis: are they important? Med Cannabis Cannabinoids. 2020;3:25-60.
49. Allen KD, McKernan K, Pauli C, Roe J, Torres A, Gaudino R. Genomic characterization of the complete terpene synthase gene family from Cannabis sativa. PLoS ONE. 2019;14(9): e0222363. https://doi.org/10.1371/journal. pone. 0222363 .

50. Bianchini AE, Garlet QI, da Cunha JA, Bandeira GJr, Brusque ICM, Salbego $J$, et al. Monoterpenoids (thymol, carvacrol and S-(+)-linalool) with anesthetic activity in silver catfish (Rhamdia quelen): evaluation of acetylcholinesterase and GABAergic activity. Braz J Med Biol Res. 2017;50(12): e6346.

51. Agatonovic-Kustrin S, Kustrin E, Morton DW. Essential oils and functional herbs for healthy aging. Neural Regen Res. 2019;14(3):441-5.

\section{Publisher's Note}

Springer Nature remains neutral with regard to jurisdictional claims in published maps and institutional affiliations.
Ready to submit your research? Choose BMC and benefit from:

- fast, convenient online submission

- thorough peer review by experienced researchers in your field

- rapid publication on acceptance

- support for research data, including large and complex data types

- gold Open Access which fosters wider collaboration and increased citations

- maximum visibility for your research: over $100 \mathrm{M}$ website views per year

At BMC, research is always in progress.

Learn more biomedcentral.com/submissions 